\title{
The Central Projections of the Stretch Receptor Neurons of Crayfish: Structure, Variation, and Postembryonic Growth
}

\author{
Michael J. Bastiania and Brian Mulloney \\ Zoology Department, University of California, Davis, California 95616
}

Each stretch receptor neuron (SR) of the crayfish abdomen projects from its peripherally located soma an axon that enters the CNS through the second nerve (N2) of its segmental ganglion. $\mathrm{Co}^{2+}$ backfills of $\mathrm{N} 2$ revealed that this axon bifurcates, sending one branch to the brain and the other to the terminal abdominal ganglion. Each axon makes many short lateral branches as it traverses each of the other segmental ganglia, and has 2 major arborizations-one in the tritocerebrum of the brain and the other in the terminal abdominal ganglion, G6. These projections to $\mathbf{G 6}$ are described in detail. Individual SR axons from different segments were impaled in G6 with a Lucifer yellow-filled microelectrode, identified physiologically, and then filled to discover their structures. In a sample of more than 50 SR neurons, no systematic structural differences between the projections of phasic SR neurons and tonic SR neurons were observed.

Three kinds of structural variability occurred in these projections to G6: unusual primary axon shape, long primary axon, and large terminal varicosities. Comparisons of SR neurons that originated in different segments revealed a segmental gradient in the probability of each structural variant. SR neurons from more anterior segments were more likely to show these structural variations. Comparisons of these variations in crayfish of different sizes showed that unusual primary axon shape and long primary axons were more probable in large crayfish than in small ones. Therefore, these variations are probably the products of postembryonic growth of the nervous system.

The stretch receptor neurons, SR 1 and SR2, are paired proprioceptive neurons whose peripherally located cell bodies and dendrites are part of the muscle-receptor organs of the decapod abdomen (Alexandrowicz, 1951, 1967). There are 2 bilateral pairs of muscle-receptor organs, $\mathrm{MRO}_{1}$ and $\mathrm{MRO}_{2}$, in each of the first 5 abdominal segments of crayfish. Two more sets occur anteriorly in the last 2 thoracic segments (Wiersma and Pilgrim, 1961). Each MRO has one SR neuron, so the animal has 28 SR neurons in all (Alexandrowicz, 1967). The MROs are associated with the dorsal extensor musculature of each segment and, in

\footnotetext{
Received Mar. 9, 1987; revised Aug. 20, 1987; accepted Sept. 29, 1987.

We thank Larisa Acevedo, Hilary Anderson, Richard Carlsen, Brad Jones, Esther Leise, David Lenzi, Nicholas Spitzer, Robert Williams, and Jeffrey Wine for critically reading various drafts of the manuscript. Supported by NIH Grants NS12295 and NS21 194 and by NSF Grants BNS 78-10516 and BNS 84-06931 to B.M. M.B. was an NIH predoctoral trainee.

Correspondence should be addressed to Prof. B. Mulloney at the above address.

a Present address: Department of Biology, University of Utah, Salt Lake, UT 84112.

Copyright (C) 1988 Society for Neuroscience $0270-6474 / 88 / 041254-10 \$ 02.00 / 0$
}

crayfish, lie just at the medial edge of the superficial medial extensor muscles. Although the 2 MROs in each hemisegment lie quite close to one another, they have distinctive anatomical and physiological characteristics (Wiersma et al., 1953; Florey and Florey, 1955) and respond to different features of abdominal movement. SR 1 responds tonically to changes in the position of the abdomen, while SR2 responds phasically to extreme or very rapid flexions of the abdomen.

The SR neurons send their axons via the second nerve, N2, into the ganglion of the next anterior segment (Fig. 1). Theirs are the largest axons in each $\mathrm{N} 2$ of the abdominal ganglia. Wiersma (1958) had physiological evidence that each SR1 projected a considerable distance from its segment of origin into the brain, but except in the ganglion of entry (Wine and Hagiwara, 1977), the structures of the projections of these axons in the CNS were unknown. It was interesting to us, then, to discover the full cxtent of the central projections made by these sensory axons and to see if we could locate sites at which the information they conveyed might be integrated. In this paper, we describe the shapes of the SR neurons in the CNS. We used both intensified $\mathrm{CO}^{2+}$ backfills of SR neurons originating in each abdominal segment and Lucifer yellow (LY) injected through microelectrodes to discover the structures of these projections. The 2 major arborizations of these neurons occur in the terminal abdominal ganglion, G6, and in the tritocerebrum of the brain. The extensive arborization in the brain is unilateral, but the arborization in G6 is bilateral. As they traverse intermediate ganglia, each $\mathrm{SR}$ projects a few lateral and medial branches that remain within the tract neuropil of the ganglion (Skinner, 1985b; Leise et al., 1987). Despite the differences in the information carried by SR 1 and SR2, we could not distinguish the structures of these neurons in the CNS; their physiological differences are not reflected in major structural differences.

There is a typical SR projection in G6 that commonly occurs, but we did observe variant structures, including terminal varicosities, long primary axons, and unusual shapes of primary axons. We found that the axons of SR neurons originating from more anterior ganglia were more likely to have one or more of these structural variants than were those from more posterior ganglia. We measured the frequencies with which these variations occurred in crayfish of different sizes and found that both terminal varicosities and long primary axons are products of postembryonic growth. We discuss these findings in the light of recent suggestions that the development of vertebrates differs in fundamental ways from that of other animals (Easter et al., 1985). In a subsequent paper we describe the physiology and variability of the PSPs that SR neurons cause in a variety of postsynaptic targets in G6 (Bastiani and Mulloney, 1988). Pre- 
liminary reports of these findings have already appeared (Bastiani and Mulloney, 1978, 1979).

\section{Materials and Methods}

Male and female crayfish, Procambarus clarkii, were obtained from Monterey Bay Hydroculture Farms (Santa Cruz, CA). Animals ranged in size from 0.5 to $13 \mathrm{~cm}$, measured from the tip of the rostrum to the end of the telson.

Dissections and backfills. We used different methods for different sizes of crayfish. Small crayfish $(<2 \mathrm{~cm})$ were cooled on ice, covered with saline (Van Ilarreveld, 1936), and pinned out, dorsal side up, in a petri dish lined with clear Sylgard (Dow-Corning). The dorsal carapace, viscera, extensor muscles, and deep flexor muscles were all removed from the level of the cervical groove to the sixth abdominal segment. The second nerve, N2, of a selected abdominal ganglion was dissected free and surrounded by a Vaseline well (Iles and Mulloney, 1971; Mulloney, 1973). The well was filled with $200 \mathrm{~mm} \mathrm{Co}\left(\mathrm{NO}_{3}\right)_{2}$ (Pitman et al., 1972), the nerve was recut in the well, and the well sealed over with Vaseline. The preparation was rinsed, covered with fresh saline, and left in a refrigerator at $4-6^{\circ} \mathrm{C}$ for as long as $36 \mathrm{hr}$. Unlike larger animals, these highly dissected small animals remained in good condition. Even after $36 \mathrm{hr}$, we observed rhythmic beating of the scaphognathite and spontaneous movement of the uropods, eyes, and antenna.

Larger animals $(>2 \mathrm{~cm}$ ) were cooled on ice and immobilized with their ventral side up and their abdomen fully extended; they were then immersed completely in saline. A window was cut in the ventral abdomen by reflecting a small flap of cuticle overlying one $\mathrm{N} 2$ of a chosen ganglion. This N2 was cut as far distally as possible, and the cut nerve was pulled up through the window and surrounded with a Vaseline well. The well was filled with $200 \mathrm{~mm} \mathrm{Co}\left(\mathrm{NO}_{3}\right)_{2}$, and the nerve was then recut in the $\mathrm{Co}^{2+}$ pool. Vaseline was used to seal the well and prevent excessive bleeding. The preparation was rinsed and covered with fresh saline. Animals were left in this condition at room temperature (20$23^{\circ} \mathrm{C}$ ) for up to $48 \mathrm{hr}$. After completion of the backfill, the Vaseline well was removed and the nervous system dissected free. Subsequent procedures were the same for both large and small animals.

Fixation, intensification, and cytology. The nervous system was rinsed in cold saline, then immersed for $15 \mathrm{~min}$ in an ammonium sulfide solution ( 2 drops $22 \%$ aq. sol. $/ 10 \mathrm{ml}$ saline) to precipitate the cobalt. The tissue was rinsed for $10 \mathrm{~min}$ in cold saline, then fixed for at least $2 \mathrm{hr}$ in $10 \%$ buffered formalin, $\mathrm{pH} \mathrm{7.0.} \mathrm{The} \mathrm{tissue} \mathrm{was} \mathrm{then} \mathrm{washed} \mathrm{in}$ distilled water and intensified (Tyrer and Bell, 1974). A slight modification of the impregnating solution gave excellent results. The impregnating solution contained $8 \%$ gum acacia, $0.15 \%$ hydroquinone, and $0.4 \%$ citrate in distilled water at $\mathrm{pH} 2.8-3.0$, adjusted with nitric acid (Bacon and Altman, 1977). The tissue was brought up to full strength impregnating solution over a period of a few hours, then developed from 10 to $30 \mathrm{~min}$ in $90 \%$ impregnating solution and $10 \%$ of a $1 \%$ silver nitrate solution. Impregnation and development was done in the dark on a slide warmer set at $45^{\circ} \mathrm{C}$. When the intensification was complete, the tissue was transferred to warm distilled water for $30 \mathrm{~min}$, then allowed to cool. The tissue was dehydrated in an ascending alcohol serics and cleared in methyl salicylate. Permanent whole mounts were made in Canada balsam. Drawings of the cells were made using a Zeiss camera lucida.

The entire central structure of an SR neuron was never seen in a single animal. The SR axons are the largest in N2, and since larger axons fill faster than smaller ones, $1-3 \mathrm{hr}$ in adults and $15-30 \mathrm{~min}$ in $20 \mathrm{~mm}$ animals were sufficient to fill the SR neurons completely in their ganglion of entry without filling extensor motor neurons or other sensory afferents. However, filling the SR neurons into the brain and the terminal abdominal ganglion required about $24 \mathrm{hr}$, which drastically overfilled the ganglion of entry and obscured the structures of the SR neurons in that ganglion.

To examine the position of SR axons and their branches in the core of G6, these ganglia were fixed and intensified after backfilling with $\mathrm{Co}^{2+}$, then postfixed with osmium, embedded in soft Spurr's resin, and sectioned. These methods are described in detail in Leise and Mulloney (1986) and Leise et al. $(1986,1987)$.

Physiolugical identification of the SR axons in the terminal ganglion G6. Animals were cooled on ice, and a window was cut in the dorsal carapace that overlies the MROs of the chosen segment. The MROs were dissected free of the extensor muscles, as described above. Each $\mathrm{N} 2$ was freed to its ganglion, and the ventral nerve cord, along with the
MROs, was removed from the abdomen and transferred to a petri dish lined with Sylgard. The nerve cord was pinned out, and 2 pairs of pin electrodes (Mulloney and Selverston, 1974) were placed on the selected N2s. A pair of stimulating electrodes was placed as far distal as possible, while a recording pair was placed near the ganglion.

Intracellular recordings from the axons of SR neurons were made with microelectrodes in G6. The sheath on the dorsal surface of G6 was removed surgically to permit microelectrodes to penetrate the core of the ganglion. The SR neurons were identified by correlating an extracellular spike with an intracellular spike that rose from a flat baseline and followed at a constant latency even at frequencies up to $200 \mathrm{~Hz}$. The SR2 neuron could be distinguished from the SR1 neuron by SR2's lower threshold to extracellular stimulation, its faster conduction velocity, and the larger amplitude of its extracellularly recorded action potential.

Microelectrodes (fiber-filled, $1 \mathrm{~mm}$ O.D.) were filled with $2.5 \mathrm{M}$ potassium acetate or $5 \% \mathrm{LY}$ dissolved in $1 \mathrm{M} \mathrm{LiCl}$ (Stewart, 1978). Acetate was preferred for physiological recording when it was necessary to pass current in order to test for electrical coupling or for the effect of presynaptic membrane potential on the size of the postsynaptic potential. These acetate electrodes had resistances between 30-60 M $\Omega$. The tips of $\mathrm{LY}$ microelectrodes were filled with $5 \% \mathrm{LY}$ dissolved in $1 \mathrm{M} \mathrm{LiCl}$ (Stewart, 1978); the shanks of the electrodes were filled with $2.5 \mathrm{M} \mathrm{LiCl}$. These microelectrodes had a resistance of 100-200 M 2 . The tips of these electrodes were then broken on the Sylgard so that their final resistance was about $80 \mathrm{M} \Omega$. The microelectrodes made contact with a Getting model 4 preamplifier through a silver chloride bridge, and the output of the preamplifier and the extracellular records from the pin electrodes were displayed on a Textronix 564 storage oscilloscope. Current was monitored with a virtual ground circuit.

After positive physiological identification, the cell was filled with LY by passing 10-20 nA hyperpolarizing pulses of $500 \mathrm{msec}$ duration at 1 $\mathrm{Hz}$ for $15-60 \mathrm{~min}$. The ganglion was immediately fixed for $10 \mathrm{~min}$ in cold $10 \%$ formalin followed by a 30 min postfix in $10 \%$ Methyl Formcel (Celanese Chemical Co.) in ethanol and then dehydrated in $100 \%$ ethanol. Ganglia were cleared in methyl salicylate and drawn at once using a Zeiss camera lucida and a fluorescence microscope.

Comparisons of anatomical methods. In our experience, LY and silver-intensified cobalt-filled SR neurons gave the same degree of resolution in whole mounts. However, the recording characteristics of electrodes filled with LY were much better than those filled with $\mathrm{Co}^{2+}$, and the histological procedures were simpler, so LY was the method of choice for studying the shapes of cclls in wholc mounts. There is no indication that artifactual swellings or varicosities result from intracellular injection of LY or the histological procedures required to see the dye-filled cells (Stewart, 1978; Bastiani, 1980, 1981).

\section{Results}

The extent of the central projection of the SR neuron is remarkable; each SR sends an axon the entire length of the CNS (Fig. 1). These axons are located medially in each connective, in Area 78 (Hughes and Wiersma, 1960). Sccondary branches of the SR neurons occurred in every segmental ganglion except the commissurals, but the most elaborate arborizations occurred in the sixth abdominal ganglion (G6) and the brain (Fig. 1). In the first abdominal ganglion of adult crayfish $(7-10 \mathrm{~cm})$, the axon of SR 2 could be as large as $25 \mu \mathrm{m}$ in diameter and that of SR 1 as large as $15 \mu \mathrm{m}$. The sizes of the axons in the ganglion of entry decreased progressively from the first to the fifth abdominal ganglion, so that the axon of SR2s entering G5 rarely exceeded $15 \mu \mathrm{m}$. This gradient followed the gradient in size of the soma of the SR neurons from anterior to posterior abdominal segments (Wiersma and Pilgrim, 1961). When both SR neurons filled the entire length of the abdominal nerve cord, there were no apparent differences in their projections, either in their destinations or in the number and length of their branches in each ganglion. Therefore, unless otherwise noted, this description of the structures of SR neurons will refer to both SR 1 and SR2. 

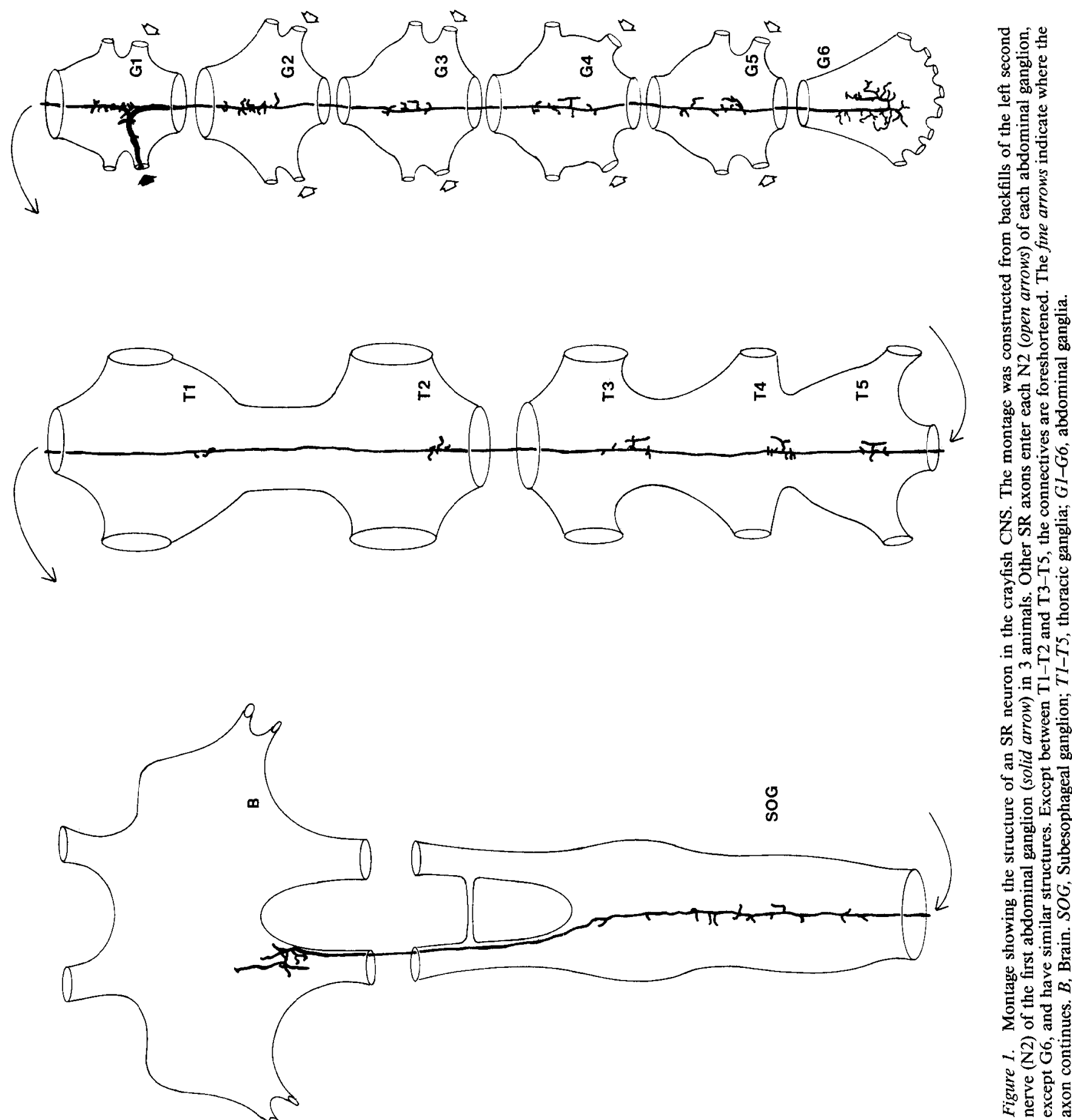
By using small crayfish, we were able to fill individual SRs from abdominal segment 1 all the way to the brain and to the terminal abdominal ganglion. The description begins with their structures in the brain and proceeds posteriorly to their structures in the terminal abdominal ganglion.

\section{Structure of the $S R$ axons in segmental ganglia and the brain}

Each SR axon entered the CNS through one of the second segmental nerves, N2, of an abdominal ganglion. Within this ganglion (Fig. 1, G1), the axon first projected medially in dorsal commissure 4 (terminology from Skinner, 1985a), then bifurcated to send processes in the dorsal median tract (DMT), both anteriorly to the brain and posteriorly to the terminal abdominal ganglion, G6. The axons of all the SRs course through each ganglion in the DMTs (Leise et al., 1987).

Within the core of the ganglion of entry, each SR axon had many short, stubby branches that were rarely longer than 100 $\mu \mathrm{m}$ in adult crayfish and were largely restricted to the same level as the DMTs. In the thoracic and other abdominal ganglia through which it passed, each SR axon had similar short branches extending both laterally and medially (Fig. 1). In some animals, some of these medial branches crossed the midline to form short T-shaped processes in the contralateral DMT (Fig. 1, T3, T4, T5), but these were not a constant feature.

In the subesophageal ganglion, which is condensed from several embryonic ganglia, each SR axon ran anteriorly near the midline (Fig. 1) and gave off branches that were only rarely longer than a third of the width of the ganglionic core. Most branches projected laterally, but T-shaped contralateral projections occurred in some animals. The axon of the SR neuron exited the subesophageal ganglion in the circumesophageal connective and did not branch as it passed the commissural ganglion.

The SR neurons had an elaborate arborization in the brain (Fig. 1). This structure was entirely ipsilateral, and most of it was restrictcd to the tritocercbrum. Onc branch, however, normally appeared to extend into the deutocerebrum. No stereotyped branching pattern was apparent. Axons of SR1 and SR2 neurons were never filled simultaneously into the brain. Multiple examples of these structures and a description of their variability can be found in Bastiani (1981).

\section{Structure of the $S R$ axons in the terminal abdominal ganglion G6}

The structures of the SR projections to G6 were more elaborate than those to the other abdominal ganglia. SR neurons from all the abdominal ganglia projected to the same dorsal area of the core of G6 and formed an almost bilaterally symmetrical U-shaped structure (Fig. 2). The structure of the SR neurons was planar, so the full extent of its shape could be seen in a frontal view. When ganglia that contained $\mathrm{Co}^{2+}$-filled $\mathrm{SR}$ axons were examined in frontal sections, the axons could be traced in the DMT as they entered G6. They ran posteriorly in the DMT until they reached the posterior end of the interconnective fissure that divides the anterior parts of G6. At this level, the axon turned medially across the midline in commissures A6 DCII or A7 DCII (terminology from Kondoh and Hisada, 1986) and turned again to run anteriorly to the end of the core of G6, where they normally terminated. Numerous branches projected laterally along the axon's entire course through the core. Only a few small branches projected medially.

The terminal branches of 52 SR neurons originating in different segments were counted from drawings of LY-filled axons.
The mean total number of terminal branches per SR neuron was $65 \pm 4 \mathrm{SE}$. The mean number of terminal branches for SR neurons from G5 and G1 did not differ significantly: G5, $76 \pm$ $9 \mathrm{SE}(n-9) ; \mathrm{G} 1,67 \pm 8 \mathrm{SE}(n-8)$.

The number of secondary branches was greater on the side ipsilateral to the SR cell body. The mean number of ipsilateral branches, $41 \pm 2 \mathrm{SE}$, was significantly larger than the mean number of contralateral branches, $24 \pm 2 \mathrm{SE}(n=52)$.

\section{$S R 1$ and SR2 form similar projections in G6}

The projections of SR 1 and SR2 had similar shapes in G6. When both ipsilateral SR neurons from the same ganglion were filled, the primary axons ran so close together that it was often impossible to distinguish them in whole mounts (Fig. 2D). The branches of both SR neurons projected laterally together (see arrows) and covered the same regions of the core. SR neurons originating in different ganglia also formed similar projections. When a group of SR neurons in Area 78 of the 5-6 abdominal connective was stripped out and backfilled with $\mathrm{Co}^{2+}$, the axons ran together and the branches were clustered together in the core (Fig. $2 C$ ). When contralateral pairs of SR neurons were filled (Fig. $2 B$ ), their primary axons overlap in the DMTs and DCII to form a continuous U-shaped structure.

Individual SR axons projecting from selected ganglia were identified physiologically as SR1 or SR2 and then filled in G6 with LY (Fig. 3). More than 50 SR1 and SR2 neurons were identified and filled. The sample included SR neurons originating in each abdominal ganglion. No structural features were found that reliably distinguished SR 1 axons from SR2 axons in G6.

\section{Variability of the structure of $S R$ projections in $G 6$}

The shapes of the projections to G6 of SR neurons originating from the more anterior ganglia were more variable than those of SRs originating in posterior abdominal ganglia (cf. Figs. 3 and 4). Three kinds of variants were observed in G6: unusual primary axon shape, long primary axon, and large terminal varicosities (Fig. 4). Primary axon shapes were considered unusual if they were not superimposable on a standard U-shaped pattern (Fig. 2). Primary axons were considered long if a primary unbranched process was longer than $150 \mu \mathrm{m}$. Terminal varicosities were considered large if they were greater than $5 \mu \mathrm{m}$ in diameter. In Figure 4, neuron D had an extremely long primary axon. Instead of terminating at the anterior edge of the contralateral core, the axon continued anteriorly in the contralateral connective for almost $1000 \mu \mathrm{m}$. The process finally terminated in a large terminal varicosity. Neuron $G$ had a very unusually shaped primary axon. This shape is not superimposable with any $U$ - or hook-shaped structure we observed. The major contralateral branch of neuron $\mathrm{H}$ appeared to end near the base of contralateral nerve 3 , not in the core of the ganglion. The typical shape of the SR projection in G6 did, however, sometimes occur in these axons of anterior SR neurons (Fig. 4, $A, B, D-F$ ).

The frequencies with which these 3 structural variants occurred were determined for 66 SR neurons originating from G1 through G5. No distinction was made between SR1 and SR2. The frequencies of these 3 variants changed systematically with their ganglion of entry (Fig. 5). The posterior-to-anterior trend for large terminal varicosities and unusual primary axon shapes was dramatic: $5 \%$ of the SR neurons from G5 exhibited these characteristics, while almost $90 \%$ of the SR neurons from G1 had large terminal varicosities and more than $60 \%$ exhibited unusual shapes. The trend of longer primary axons was not as 

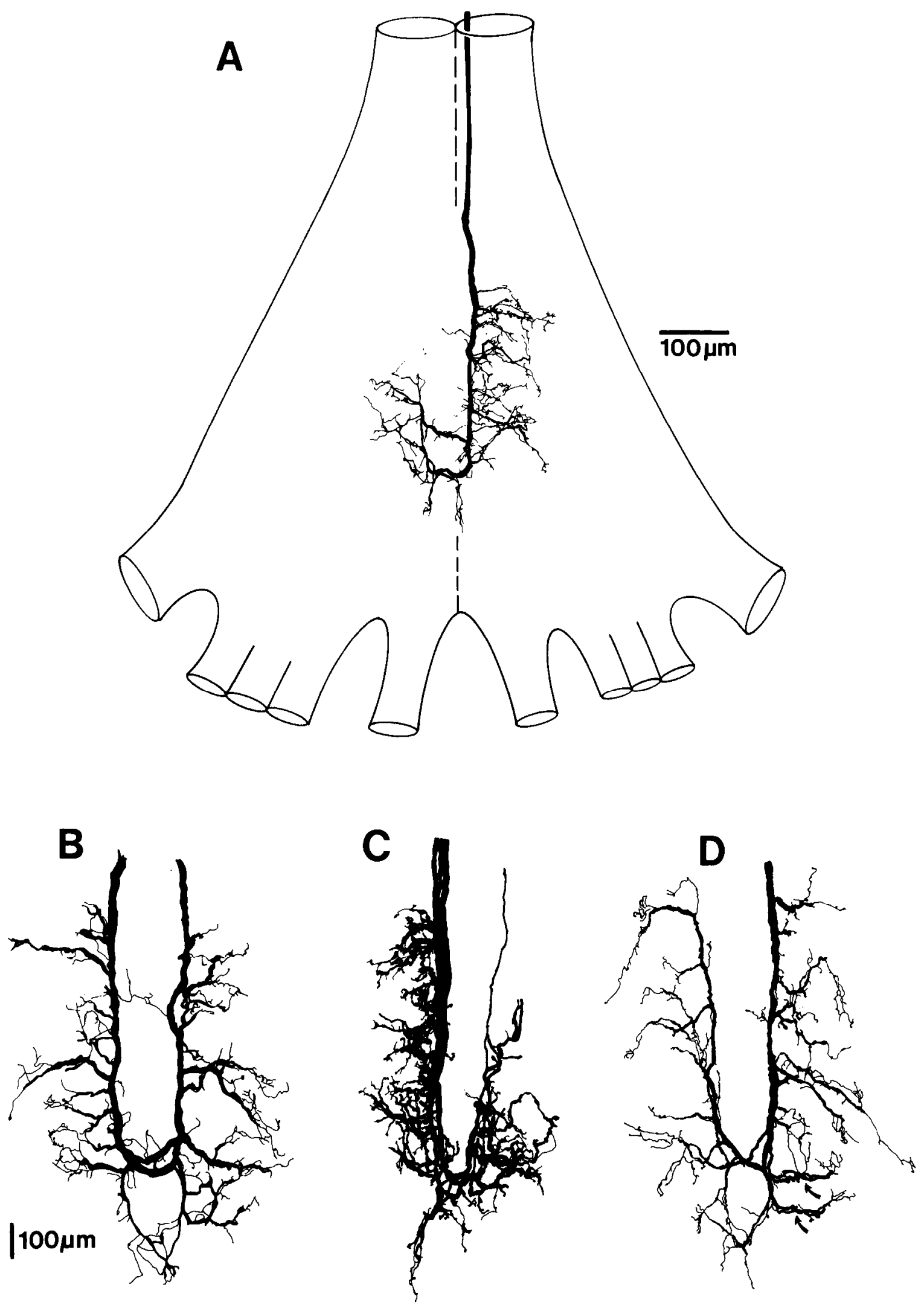

Figure 2. A, Camera lucida drawing of the axonal projections of SR1 and SR2 in G6, filled with Co ${ }^{2+}$ from the right $\mathrm{N} 2$ of G5. Frontal view, with anterior at the top. $B$, Bilateral pair of SR neurons filled from the right and left N2s of G5. $C$, Bundle of SR axons, filled from the connective between G5 and G6. D. Ipsilateral SR1 and SR2 axons, filled with $\mathrm{Co}^{2+}$ from G5. Notice the extensive overlap of both the axon and the primary branches. Arrows show 2 examples of SR1 and SR2 primary branches twisted together. Adult crayfish. 


\section{SR1}
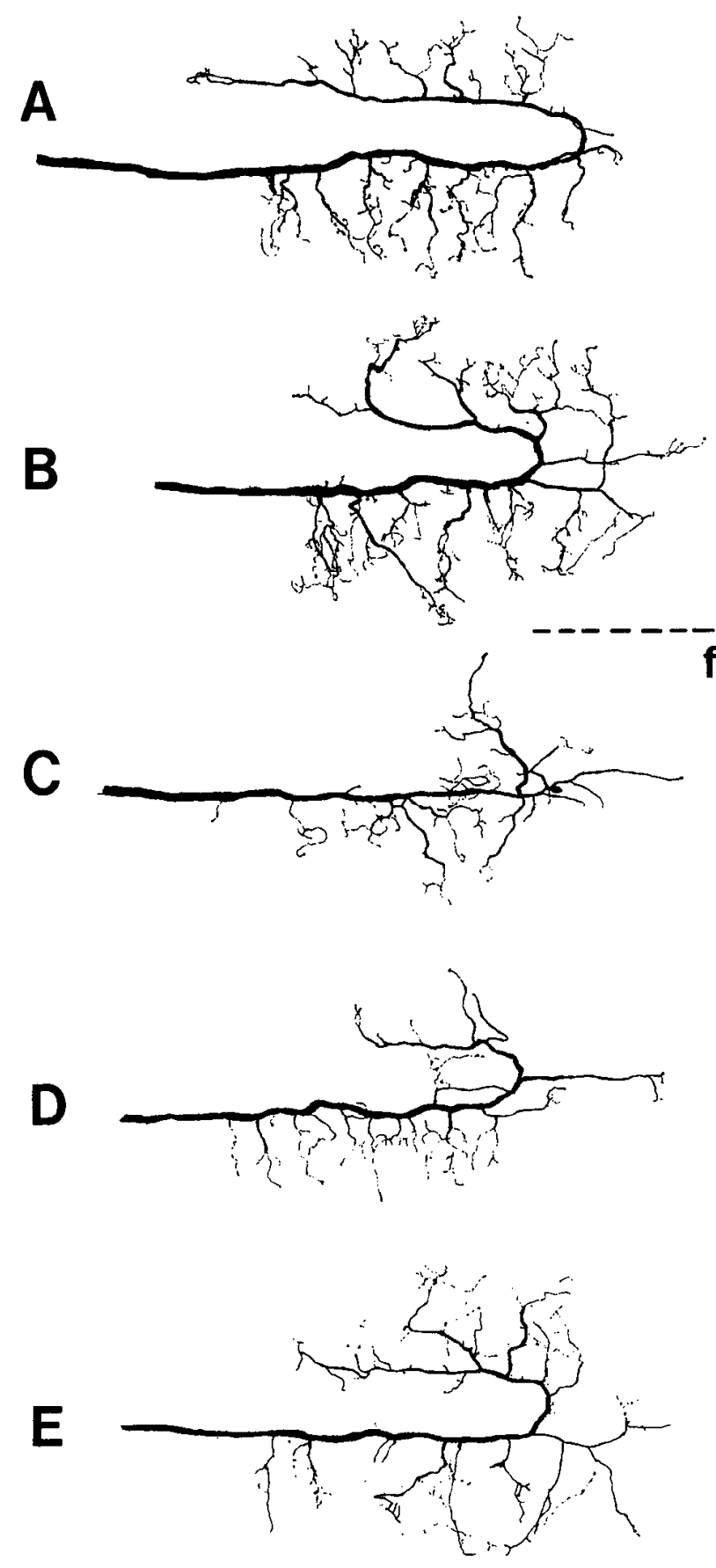

\section{SR2}

\section{from G4}
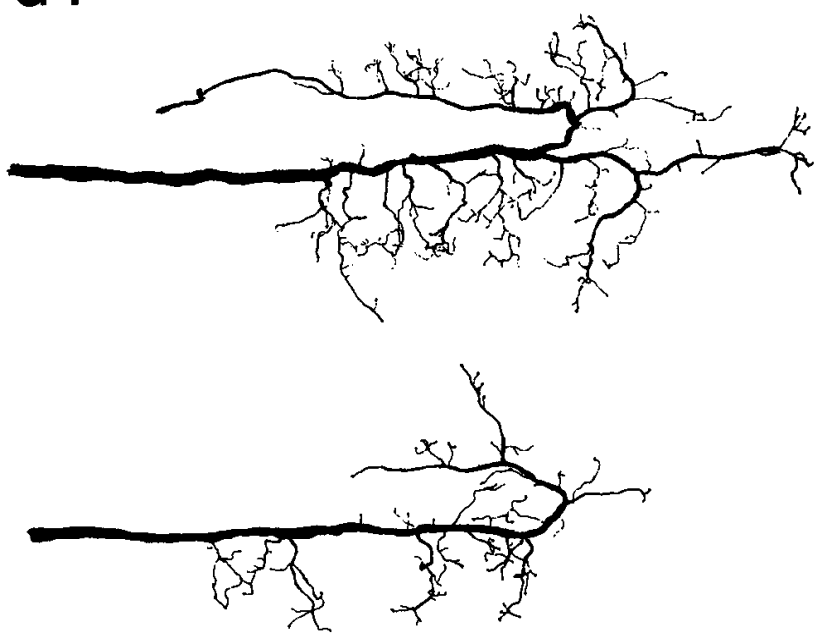

from $G 5$
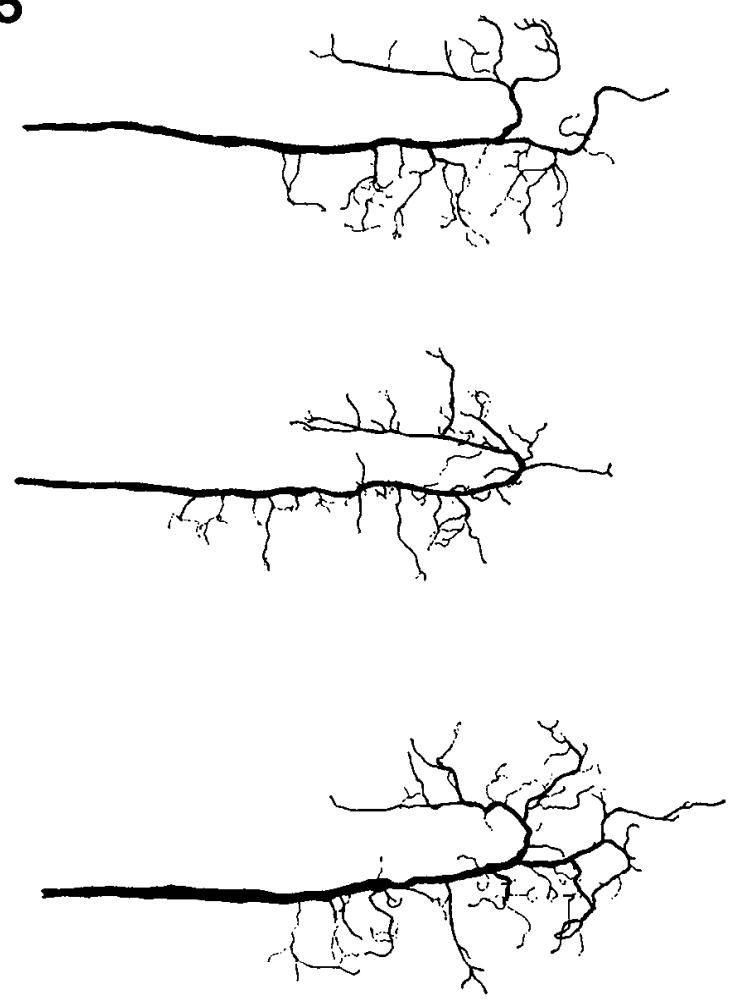

\section{$\overline{100} \mu \mathrm{m}$}

Figure 3. Structurcs of SR1 and SR2 axons in G6. Frontal drawings made from whole mounts with a camera lucida. $A$, and $B$, SR neurons filled from $\mathrm{G} 4$. $C-E$, SR neurons filled from $\mathrm{G} 5$. Adult crayfish. 

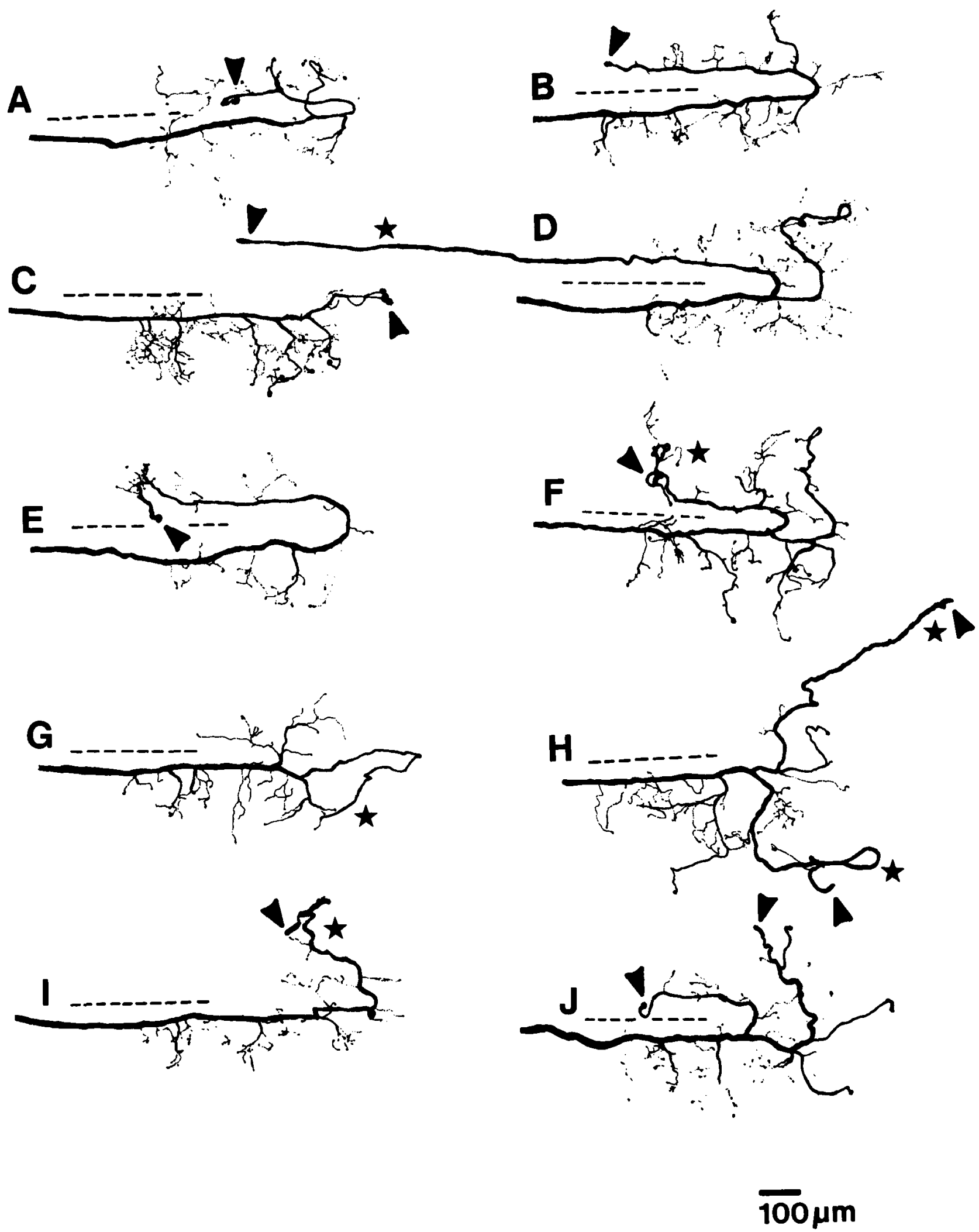

Figure 4. Ten examples of the structures formed in G6 by SR axons that originated in G1 or G2. These axons were identified physiologically, then filled with LY and drawn if frontal view with a camera lucida. The dashed lines indicate the midlines of the ganglia. $\mathbf{\Lambda}$, Large varicosities; *, long primary axon. 


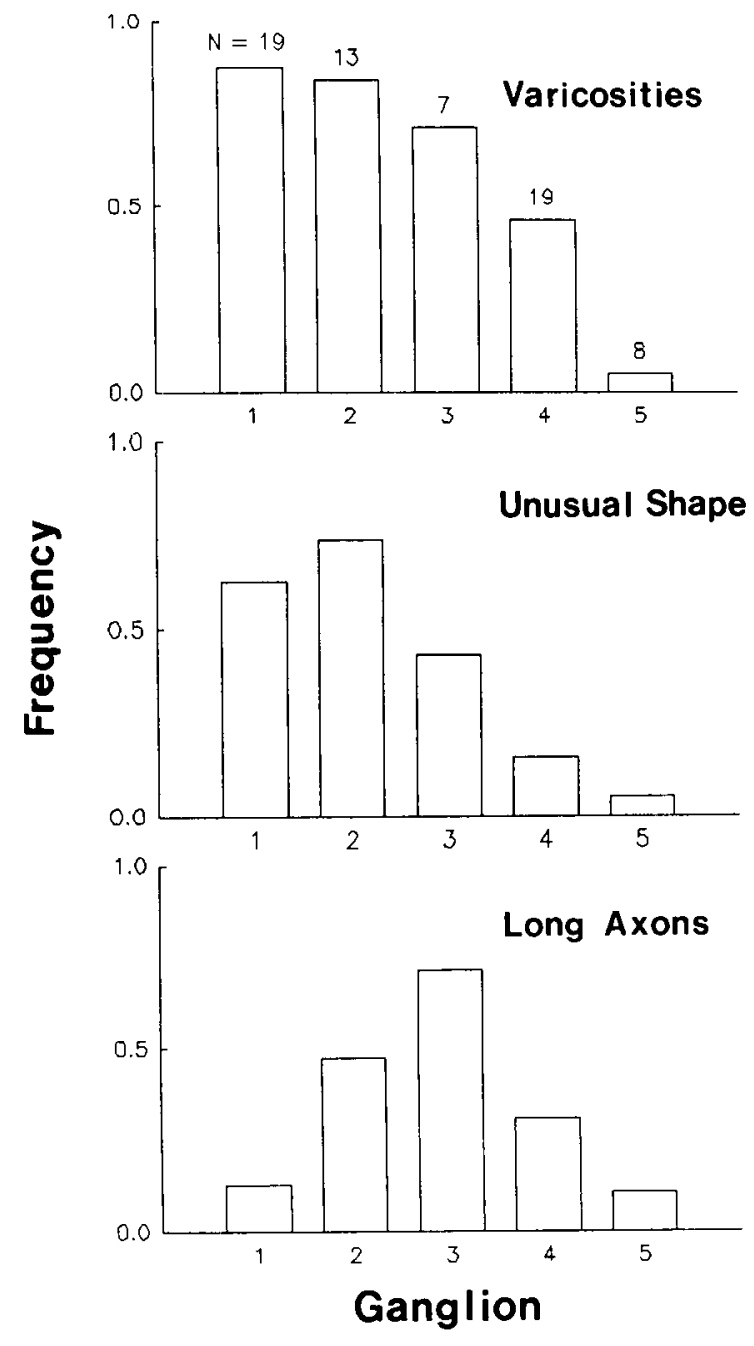

Figure 5. Posterior-anterior gradients of morphological variability of SR axons in G6. $N$ is the number of SR axons from each abdominal ganglion $(1 \ldots 5)$ that were examined for structural variants. The classes of variations are defined in the text.

simple. Long primary axons occurred in $10 \%$ of the SR neurons from G5, $70 \%$ of the SR neurons from G3, and $12 \%$ of the SR neurons from $\mathrm{G} 1$. Long primary axons were accompanied by large terminal varicosities, but the converse was not necessarily true; compare these features for Gl (Fig. 5). This suggests that large terminal varicosities might precede the appearance of excessive tcrminal growth.

\section{These variants have a postembryonic origin}

To determine if these unusual characteristics of the SR neurons' structure originated during embryonic development or during the animal's protracted postembryonic growth, we compared their frequencies in SR neurons from G3 that were filled in hatchlings $(0.5 \mathrm{~cm})$, small crayfish $(1-2 \mathrm{~cm})$, and adults $(10 \mathrm{~cm})$. The linear dimensions of the core of G6 increase 3-fold as the crayfish grows from 0.5 to $10.0 \mathrm{~cm}$, so its volume increases about 30 -fold. An unusual axon shape occurred in some neurons from animals of all 3 sizes, but long primary axons and large terminal varicosities were not observed in hatchlings or small animals (Fig. 6). A $\chi^{2}$ analysis of these differences, which used the measured adult frequencies as the expected frequencies in all sizes of crayfish, found no significance to the observed dif-

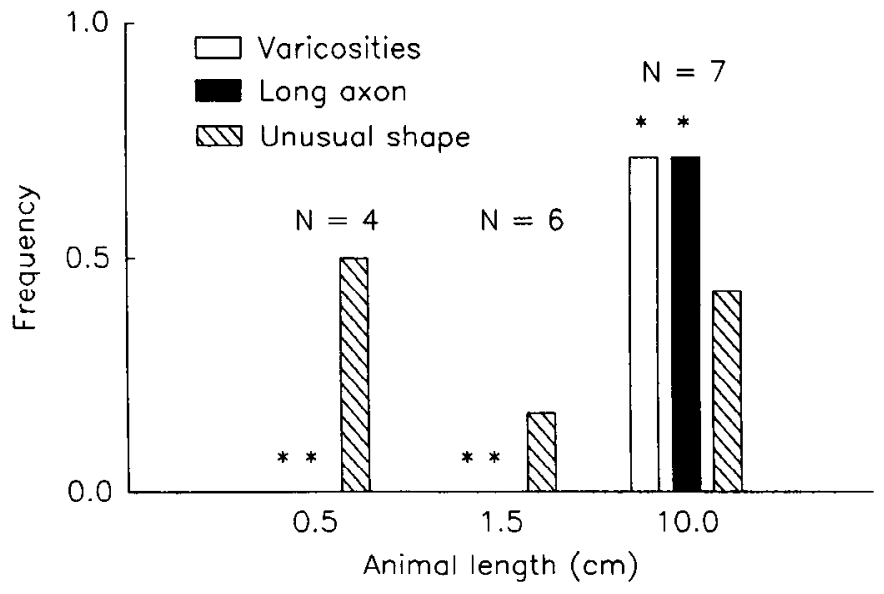

Figure 6. Frequency of structural variability in crayfish of different sizes. The data for adults were obtained from LY-filled neurons. The data for hatchlings and small crayfish were obtained from neurons filled with $\mathrm{Co}^{2+} . N$ is the number of neurons scored in animals of each size. * Significantly different $(p<0.001)$.

ferences in the frequencies of unusual shapes. The frequencies of terminal varicosities and long primary axons in the hatchling and small crayfish differed significantly from those of adults $(p<0.001)$. These observations suggest that the posterior-toanterior trend in unusual axon shapes arises during embryonic development, while the large terminal varicosities and longer primary axons develop during the postembryonic growth of the crayfish nervous system.

\section{Discussion}

The most remarkable feature of the SR neurons is that their axons travel the entire length of the crayfish CNS to branch and perhaps to synapse in every ganglion but one. Only one other kind of primary afferent in these animals, the N-cells of the thorax (Alexandrowicz, 1952), is known to project more than 3 or 4 ganglia, and these are probably homologs of the SR neurons. Why do the SR neurons project the entire length of the CNS? The long projection of the SR neurons would allow their direct convergence from all the abdominal segments onto neurons important for integrated movements of the whole body. The comparatively elaborate structures of these SR neurons in G6 and the tritocerebrum point to these 2 regions as centers for the coordination of whole-body movements. G6 is the only ganglion that receives a large and consistent contralateral projection from the SR neurons.

Comparisons of the structures of individual SR1 and SR2 neurons established that the central structures of these 2 neurons cannot be distinguished by shape alone. Both neurons have branches in the same dorsal region of the ganglionic core, and, in some instances, the branches of SR 1 and SR2 twist together. This is surprising, since these different neurons carry different kinds of information. The close association of their branches in G6 suggests either that they share the same postsynaptic cells or that they synapse with each other. We have observed that about $60 \%$ of the neurons postsynaptic to SRs in G6 synapse with both SR1 and SR2 axons (Bastiani and Mulloney, 1988). However, in this same ganglion about $20 \%$ synapsed exclusively with SR 1 and $20 \%$ exclusively with SR2, so some target neurons are able to distinguish these afferents during the initial development of the CNS. 


\section{Normal projections to $G 6$}

We considered the frequency of variability of SR axons from G1 to be higher than that of SR axons from G5 (Fig. 5), but one might consider $\mathrm{G} 1$ as the norm rather than G5 because the frequencies of G5-like structures in axons originating from $\mathrm{Gl}$ was quite low. Two lines of evidence speak against this argument. The shapes of SRs from G1 were not merely different from those from G5, they were also much more variable in themselves. The array of shapes of Gl axons in G6 did not form a reproducible alternative to the characteristic shape of SR axons from G5 (cf. Figs. 3 and 4). Another line of evidence comes from the properties of PSPs recorded in neurons postsynaptic to SRs in G6. In neurons that received synaptic input from SR neurons originating in several different segments, the probability that an SR from an anterior segment would fail to synapse with a given postsynaptic neuron was greater than that of an SR neuron from a more posterior segment (Bastiani and Mulloney, 1988). The absence of a reproducible alternative shape from $\mathrm{Gl}$ and the higher probability of missed synapses from anterior segments justify the choice of the G5 projections as the typical SR projections in G6.

\section{Structural variability and its sources}

Previous studies of structural variability in identified neurons have pointed to genetic variability and to inbreeding of laboratory stocks for the abundance of such variability where it has been observed. For example, Goodman (1974) reported both variation in the structures of ocellar interneurons and variability in their numbers and used isogenic lines of grasshoppers to estimate the relative contributions of genetic and developmental factors to these structural variants (Goodman, 1977). Other locust interneurons, the DCMDs, also have occasional structural variants (Goodman et al., 1979). Pearson and Goodman (1979) and Steeves and Pearson (1983) correlated the absence of characteristic branches of these interneurons with the absence of their PSPs in identified target neurons. Altman and Tyrer (1977) demonstrated similar occasional odd projections in the wing stretch-receptor afferents of locusts. In all these studies, genetic variability that had accumulated in inbred stocks was held to be the proximate cause of the aberrant development, and its significance for normal development in outbred populations was unclear. The results we report differ in this respect from these previous reports. The colonies from which our crayfish came were large, consisting of thousands of animals, and had not been long established. They were regularly augmented with newly captured wild crayfish, so significant inbreeding was unlikely. Furthermore, natural selection for effective, rapid movement is as stringent in a commercial colony as it would be in the wild; crayfish are aggressive cannibals. It is therefore likely that the structural variants that we observed occur in all crayfish populations.

The SR neurons are identifiable and occur in animals with determinate development, yet some show these curious variations in structure. What might be the causes of these variants? The equivalent frequencies of unusual primary axon shapes in newly hatched and adult crayfish suggest that these variants arise during embryonic development, perhaps due to variability in axonal pathfinding. The increased frequencies of both long primary axons and terminal varicosities in adults, however, argues for continued growth or development of these neurons during postembryonic life. Crayfish grow by molting their exoskeletons, and at each molt, new sensory afferents are added from newly differentiated hairs (Letourneau, 1976). The SR neurons are constant in number from the first postembryonic stages of life (Allen, 1894), but their projections in the CNS may not simply increase in volume as the animal grows but may actively form new synapses along with the newly differentiated afferents.

The evidence presented here for postembryonic growth of these sensory axons in the CNS comes from careful examination of a well-defined set of neurons in a large number of animals. Recently, the case has been put that the development of the brains of vertebrates differs from that of other animals because it continues past the embryonic stages and adapts to the experience of the individual animal (Easter et al., 1985). From this perspective, studies of the development of arthropods whose brains consist of uniquely identifiable neurons with structures and properties constant from one animal to the next seem unlikely to provide insights that might inform our understanding of vertebrate development. We suggest that this view could be seriously advocated only because so many analyses of arthropod development have concentrated on individual neurons and have discarded as artifacts those examples that did not conform to the stereotype. Murphey (1986) has recently reviewed the evidence for competition and synaptic remodeling in the development of the insect CNS. Wilson (1968) had earlier demonstrated inherent asymmetries in the flight performance of individual locusts, asymmetries that reflected individual differences in the performance of the central pattern-generating circuits for flight. The evidence presented here for variability and postembryonic growth of the SR neurons is another example of the similarity of developmental mechanisms in vertebrates and arthropods. In the companion paper (Bastiani and Mulloney, 1988), we present evidence of the uncertainty of the synapses made by these central projections of SR axons.

\section{References}

Alexandrowicz, J. S. (1951) Muscle receptor organs in the abdomen of Homarus vulgaris and Palinurus vulgaris. Q. J. Microsc. Sci. 92: 163-199.

Alexandrowicz, J. S. (1952) Receptor elements in the thoracic muscles of Homarus vulgaris and Palinurus vulgaris. Q. J. Microsc. Sci. 93: $315-346$

Alexandrowicz, J. S. (1967) Receptor organs in the thoracic and abdominal muscles of crustacea. Biol. Rev. 42: 288-326.

Allen, E. J. (1894) Studies on the nervous system of crustacea: I. Some nerve-elements of the embryonic lobster. Q. J. Microsc. Sci. 36:461482.

Altman, J. S., and N. M. Tyrer (1977) The locust wing hinge stretch receptors. II. Variation, alternative pathways and "mistakes" in the central arborizations. J. Comp. Neurol. 172: 431-440.

Bacon, J. P., and J. S. Altman (1977) A silver intensification method for cobalt-filled neurons in wholemount preparations. Brain Res. 138 . 359-363.

Bastiani, M. J. (1980) The central structure of the stretch receptor neurons of crayfish. M.S. thesis, University of California, Davis.

Bastiani, M. (1981) The central anatomy and physiology of the stretch receptor neurons of the crayfish. Ph.D. thesis, University of California, Davis.

Bastiani, M., and B. Mulloney (1978) Central anatomy of the crayfish stretch receptor neurons. Soc. Neurosci. Abstr. 4: 1227.

Bastiani, M., and B. Mulloney (1979) A posterior to anterior gradient in variability of the structures of two identified neurons in crayfish. Soc. Neurosci. Abstr. 5: 481.

Bastiani, M. J., and B. Mulloney (1988) The central projections of the stretch receptor neurons of crayfish: Segmental gradients of synaptic probability and strength. J. Neurosci. 8: 1264-1272.

Easter, S. S., Jr., D. Purves, P. Rakic, and C. Spitzer (1985) The changing view of neural specificity. Science 230: 507-511. 
Florey, E., and E. Florey (1955) Microanatomy of the abdominal stretch receptors of the crayfish (Astacus fluviatilis L.). J. Gen. Physiol. 39: 69-85.

Goodman, C. S. (1974) Anatomy of locust ocellar interneurons: Constancy and variability. J. Comp. Physiol. 95: 185-201.

Goodman, C. S. (1977) Neuron duplications and deletions in locust clones and clutches. Science 197: 1384-1387.

Goodman, C. S., K. G. Pearson, and W. J. Heitler (1979) Variability of identified neurons in grasshoppers. Comp. Biochem. Physiol. 64A: 455-462.

Hughes, G. M., and C. A. G. Wiersma (1960) Neuronal pathways and synaptic connections in the abdominal cord of the crayfish. J. Exp. Biol. 37: 291-307.

Iles, J. F., and B. Mulloney (1971) Procion yellow staining of cockroach motor neurones without the use of microelectrodes. Brain Res. 30 . $397-400$.

Kondoh, Y., and M. Hisada (1986) Neuroanatomy of the terminal (sixth abdominal) ganglion of the crayfish, Procambarus clarkii. Cell Tissue Res. 243: 273-288.

Leise, E. M., and B. Mulloney (1986) The osmium-ethyl gallate procedure is superior to silver impregnations for mapping neuronal pathways. Brain Res. 367: 265-272.

Leise, E. M., W. M. Hall, and B. Mulloney (1986) Functional organization of crayfish abdominal ganglia. I. The flexor systems. J. Comp. Neurol. 253: 25-45.

Leise, E. M., W. M. Hall, and B. Mulloney (1987) Functional organization of crayfish abdominal ganglia. II. Sensory afferents and extensor motor neurons. J. Comp. Neurol. 266: 495-518.

Letourneau, J. G. (1976) Addition of sensory structures and associated neurons to the crayfish telson during development. J. Comp. Physiol 110: 13-23.

Mulloney, B. (1973) Microelectrode injection, axonal iontophoresis, and the structure of neurons. In Intracellular Staining in Neurobiology, Kater and Nicholson, eds., pp. 99-114, Springer, New York.

Mulloney, B., and A. I. Selverston (1974) Organization of the stomatogastric ganglion of the spiny lobster. I. Neurons driving the lateral teeth. J. Comp. Physiol. 91: 1-32.

Murphey, R. K. (1986) The myth of the inflexible invertebrate: Competition and synaptic remodelling in the development of invertebrate nervous systems. J. Neurobiol. 17: 585-591.
Pearson, K. G., and C. S. Goodman (1979) Correlation of variability in structure with variability in synaptic connections of an identified interneuron in locust. J. Comp. Neurol. 184: 141-165.

Pitman, R. M., D. C. Tweedle, and M. J. Cohen (1972) Branching of central neurons: Intracellular cobalt injection for light and electron microscopy. Science 176: 412-414.

Shepherd, D., and R. K. Murphey (1986) Competition regulates the efficacy of an identified synapse in crickets. J. Neurosci. 6: 31523160 .

Skinner, K. (1985a) The structure of the fourth abdominal ganglion of the crayfish, Procambarus clarkii. I. Tracts in the ganglionic core. J. Comp. Neurol. 234: 168-181.

Skinner, K. (1985b) The structure of the fourth abdominal ganglion of the crayfish, Procambarus clarkii. II. Synaptic neuropils. J. Comp. Neurol. 234: 182-191.

Steeves, J. D., and K. G. Pearson (1983) Variability in the structure of an identified interneurone in isogenic clones of locusts. J. Exp. Biol. 103: $47-54$.

Stewart, W. W. (1978) Functional connections between cells as revealed by dye-coupling with a highly fluorescent naphthalimide tracer. Cell 14:741-759.

Tyrer, N. M., and Bell, E. M. (1974) The intensification of cobaltfilled neurone profiles using a modification of Timm's sulphide-silver method. Brain Res. 73: 151-155.

Van Harreveld, A. (1936) A physiological solution for fresh water crustaceans. Proc. Soc. Exp. Biol. (NY) 34: 428-432.

Wiersma, C. A. G. (1958) On the functional connections of single units in the central nervous system of the crayfish, Procambarus clarkil (Girard). J. Comp. Neurol. 110: 421-471.

Wiersma, C. A. G., and R. L. Pilgrim (1961) Thoracic stretch receptors in crayfish and rocklobster. Comp. Biochem. Physiol. 2: 51-64.

Wiersma, C. A. G., E. Furshpan, and E. Florey (1953) Physiological and pharmacological observations on muscle receptor organs of the crayfish, Cambarus clarkii (Girard). J. Exp. Biol. 30: 136-150.

Wilson, D. M. (1968) Inherent asymmetry and reflex modulation of the locust flight motor pattern. J. Exp. Biol. 48: 631-641.

Wine, J. J., and G. Hagiwara (1977) Crayfish escape behavior: I. The structure of efferent and afferent neurons involved in abdominal extension. J. Comp. Physiol. 121: 145-172. 